\title{
A TUTELA DOS DIREITOS HUMANOS EM UM ESTADO DEMOCRÁTICO DE DIREITO: UMA ANÁLISE CRÍTICA DA JUDICIALIZAÇÃ̃ DAS POLÍTICAS PÚBLICAS DE SAÚDE NO BRASIL
}

\author{
THE PROTECTION OF HUMAN RIGHTS IN A DEMOCRATIC STATE \\ LAW: A CRITICAL ANALYSIS OF JUDICIALIZATION PUBLIC POLITICS HEALTH \\ IN BRAZIL
}

\begin{abstract}
Resumo
O presente estudo consiste em uma análise crítica acerca da judicialização das políticas públicas de saúde no Brasil, que perpassa uma compreensão quanto ao que hodiernamente chamamos Direitos Humanos, bem como uma avaliação do papel do Estado Democrático de Direito enquanto ente que possui como um de seus fundamentos a dignidade da pessoa humana. $\mathrm{O}$ estudo possui caráter qualitativo e a metodologia adotada consiste fundamentalmente em pesquisa bibliográfica e jurisprudencial. Através desta abordagem, traçamos uma reflexão relevante para o cenário brasileiro atual, que, através da compreensão das bases dos direitos e deveres inerentes a tal discussão, busca analisar a situação fática existente, ao final concluindo pela urgência em adotar medidas efetivas para solucionar o problema sob pena de incidirmos em um verdadeiro colapso do sistema de saúde do país.
\end{abstract}

Palavras-chave: Direitos Humanos; Estado Democrático de Direito; Judicialização; Políticas Públicas, Saúde.

\begin{abstract}
This study consists of a critical analysis of the judicialization of public health policies in Brazil, which runs through an understanding as to what our times call Human Rights, as well as an evaluation of the role of the Democratic Rule of Law that has as one of its grounds the dignity of the human person. The study has a qualitative approach and methodology adopted consists fundamentally of literature and jurisprudence. Through this approach, we draw a reflection relevant to the current Brazilian scenario, that by understanding the basis of rights and duties inherent in such a discussion, seeks to analyze the factual situation existing at the end of completing the urgency to adopt effective measures to solve the problem under penalty of inside in a real collapse of the health system of the country.
\end{abstract}

Keywords: Human Rights; Democratic Rule of Law; Judicialization; Public Policies; Health.

\section{INTRODUÇÃO}


Para que possamos desenvolver uma análise crítica acerca da judicialização das políticas públicas na área de saúde em nosso país, faz-se necessário entender as bases dos direitos e deveres inerentes a tal discussão.

Neste sentido, mister que possamos compreender o contexto evolutivo e histórico quanto ao que hodiernamente chamamos Direitos Humanos, avaliar a evolução das formas de Estado e o papel do Estado Democrático de Direito enquanto ente que possui como fundamento a dignidade da pessoa humana, bem como o direito positivo a nível internacional - quanto à tutela dos direitos humanos - e a nível nacional - quanto à proteção dos direitos fundamentais.

Por esta razão, o presente estudo busca inicialmente contextualizar, ainda que de forma breve e superficial, os direitos humanos para logo após analisar a evolução do Estado nos últimos séculos, iniciando no Estado Liberal e culminando no Estado Democrático de Direito. Em um segundo momento se faz necessário situar o direito à saúde como direito fundamental relacionado com o direito à vida, bem como localizá-lo na Declaração Universal dos Direitos Humanos e na legislação brasileira vigente.

Após estas etapas teremos construído o embasamento mínimo para que seja possível adentrar o cerne a que o estudo propõe.

A judicialização das políticas públicas de saúde, apesar de não ser um tema novo a ser analisado, ainda possui interfaces que merecem um debate muito mais aprofundado.

Face ao exposto, passaremos a analisar, de forma pormenorizada, as seguintes questões basilares: a) a intervenção do Judiciário pode ser equiparada a um saneamento das omissões do Estado Democrático de Direito na atenção ao direito fundamental à saúde, igualmente preconizado na Declaração Universal dos Direitos Humanos de 1948? Ou então o exponencialmente crescente excesso de ordens judiciais poderá, a curto prazo, inviabilizar a universalidade da saúde, um dos fundamentos do SUS? c) há razoabilidade na intervenção do Judiciário nas políticas públicas que por lei competem ao Executivo? d) quais as alternativas viáveis para iniciarmos o saneamento de tão expressivo problema, se é que ainda há solução para tal?

Este estudo possui caráter qualitativo e a metodologia adotada consiste fundamentalmente em pesquisa bibliográfica, que tem como pressuposto a leitura, a análise e a interpretação de textos e/ou documentos que contemplem o tema abordado. 


\section{UMA BREVE CONTEXTUALIZAÇÃO TEÓRICA ACERCA DOS DIREITOS HUMANOS}

Antes de adentrarmos esta sucinta contextualização, imperioso destacar que, em que pese tenhamos nos deparado com importantes autores como Lucas que defendem a desvinculação dos direitos humanos de um caráter meramente histórico ${ }^{1}$, para fins de situar o leitor, utilizaremos nesta pesquisa uma versão clássica adotada por Norberto Bobbio (2004) e outros teóricos quanto ao contexto no qual os mesmos se desenvolveram.

Entretanto, cabe destacar que Lucas propõe evitarmos uma argumentação acerca da fundamentação dos direitos humanos baseada na tradição e em relativismos históricos a historicidade - eis que:

é evidente que o homem vive inserido numa situação histórica; não há como fugir desta contingência, no entanto as normas que são produzidas no contexto desta dada situação histórica não podem ser justificados tão somente a partir da história como tal (2010, p. 33).

Entretanto, não queremos aqui buscar uma justificação meramente histórica, mas sim compreender o surgimento dos direitos humanos inseridos em um referencial histórico.

Dito isso, podemos afirmar que desde os primórdios, a civilização humana percorreu um extenso caminho, tendo sofrido inúmeras transformações, sejam elas de cunho social, político, religioso ou econômico. Estas etapas - ou fases - da evolução humana possuem inúmeras peculiaridades, tendo se desenvolvido de forma gradual e em consonância com as evoluções científicas, tecnológicas, sociais e jurídicas havidas ao longo dos séculos.

$\mathrm{O}$ desenvolvimento dos direitos inerentes à pessoa humana igualmente ocorreu de forma lenta e gradual, ou seja, esses direitos não foram reconhecidos a um só tempo. Assim, podemos dizer que o desenvolvimento e as mutações sofridas pela humanidade ocasionaram, gradualmente, transformações no elenco dos direitos do homem. Tais direitos, evidentemente, continuam a se modificar, acompanhando as transformações sociais.

\footnotetext{
${ }^{1}$ Para um maior aprofundamento acerca do problema da universalidade dos direitos humanos e o relativismo de sua efetivação histórica ver LUCAS, Doglas Cesar. Direitos humanos e interculturalidade: um diálogo entre a igualdade e a diferença. Ijuí: Unijuí, 2010.
} 
$\mathrm{Na}$ história da formação das declarações de direitos podemos destacar, ao menos, três fases distintas. Na primeira fase, as declarações se originam como teorias filosóficas nas quais o homem, enquanto tal, tem direitos que ninguém - nem mesmo o Estado - lhe pode subtrair (jusnaturalismo moderno). Na segunda fase, pela primeira vez, tais teorias passam a ser acolhidas por um legislador, o que ocorre a partir da Declaração de Direitos do Povo da Virgínia - 1776 e da Declaração do Homem e do Cidadão - 1789, muito embora os direitos do homem ainda sejam considerados somente enquanto direitos do cidadão deste ou daquele Estado em particular. Por fim, a terceira fase teria seu nascedouro em 1948, com a Declaração Universal dos Direitos Humanos, na qual a afirmação dos direitos passa a ser aceita como universal e positiva (BOBBIO, 2004, p.28).

Segundo os ensinamentos de Morais e Spengler (2012, p.16), os Direitos Humanos "são históricos e se formulam quando e como as circunstâncias sócio-históricopolítico-econômicas são propícias ou referem a inexorabilidade do reconhecimento de novos conteúdos".

Neste diapasão, a doutrina estuda os Direitos Humanos como divididos em gerações, ou mesmo dimensões, como preferem denominar alguns autores como, por exemplo, Paulo Bonavides (1997).

A expressão dimensão substituiria o termo geração com substanciosa vantagem lógica e qualitativa, caso este último fosse entendido apenas por uma sucessão cronológica, trazendo, consigo a ideia de uma suposta caducidade dos direitos contidos nas gerações antecedentes (BONAVIDES, 1997, p. 525).

Em que pese a louvável e coerente doutrina Bonavides - dentre outros - estar pautada na utilização da expressão dimensão de modo a evitar a errônea interpretação no sentido da superação geracional, optamos, neste estudo, por utilizar a expressão geração, eis que adotada pela maioria dos autores.

Assim, poderíamos estabelecer uma ordenação histórica dos Direitos Humanos em cinco grandes gerações. A primeira geração de Direitos Humanos estaria ligada aos direitos civis e políticos (liberdade, propriedade, segurança, resistência às diversas formas de opressão) - liberdades negativas. A segunda geração, vinculada aos direitos econômicos, culturais e sociais - liberdadedes positivas. Já a terceira, relativa aos direitos que afligem os homens em conjunto, ou seja, direitos meta-individuais, direitos coletivos e difusos, direitos de solidariedade (incluem-se aqui os direitos relacionados ao 
desenvolvimento, à paz, à autodeterminação dos povos, ao meio ambiente sadio, à qualidade de vida, ao direito de comunicação).

Mais recentemente a doutrina passou a falar em uma quarta e uma quinta gerações. A quarta estaria ligada aos direitos referentes à biotecnologia, à bioética e à regulação da engenharia genética, enquanto a quinta geração estaria conectada à ideia das tecnologias de informação (internet, redes/comunidades virtuais, ciberespaço).

De outra banda, com vistas a uma boa compreensão acerca da evolução dos Direitos Humanos e os principais obstáculos e desafios contrapostos a eles na atualidade, imperioso analisá-los em paralelo com o desenvolvimento do Estado moderno, sob um prisma transdisciplinar.

Para Wolkmer (2002, p. 11), “o processo de reconhecimento e afirmação de direitos chamados 'humanos' ou 'fundamentais' constituiu uma verdadeira conquista da sociedade moderna ocidental".

Por fim, antes de abordarmos com certo detalhamento o surgimento do Estado Democrático de Direito e posteriormente adentrar o âmago da discussão quanto à judicialização das políticas públicas, poderíamos dizer, sem sombra de dúvida, que os Direitos Humanos - como direitos fundamentais e universais - materializam exigências e necessidades permanentes da própria sociedade e em constante transformação diante das condições emergentes da vida social e das inúmeras prioridades determinadas pela evolução e pelo desenvolvimento contínuo do ser humano.

\section{O CONTEXTO HISTÓRICO DO SURGIMENTO DO ESTADO DEMOCRÁTICO DE DIREITO}

O Estado Democrático de Direito surgiu após uma evolução histórica nas formas de Estado, ou seja, possui uma história constitucional que pretendemos aqui delinear de forma abreviada, e cujo nascedouro poderíamos considerar como sendo o Estado Liberal e o fim, o próprio Estado Democrático de Direito como tal.

Neste diapasão, podemos dizer que o Estado Democrático Direito é resultado de um processo evolutivo iniciado pelo Estado Liberal que, tendo perpassado pelo Estado Social 
de Direito, transmuta-se finalmente na forma de Estado Democrático de Direito a qual conhecemos na atualidade.

A forma inicial, ou seja, o Estado de Direito é um Estado tipicamente liberal e constitucional surgido em um contexto histórico de passagem da Monarquia absolutista para a Monarquia Constitucional, cujas características, segundo a doutrina de José Afonso da Silva são a submissão ao império da lei, a divisão de poderes e o enunciado e garantia dos direitos individuais (1999, p. 112). Afora estas características poderíamos acrescentar igualmente a rigidez e supremacia constitucional, bem como o controle de constitucionalidade das leis.

Diante disto, poderíamos asseverar que o Estado de Direito se baseia estritamente no princípio da legalidade, reduzindo-se o Direito à mera lei, de modo a superar a dicotomia entre direito natural e direito positivo, isto porque não se concebia a existência de outro direito, senão o positivo.

Marcado pela expressão laissez faire ${ }^{2}$, o Estado Liberal foi um Estado de políticas abstencionistas cujo cerne foi o princípio da liberdade.

Entretanto, apenas a liberdade não foi capaz de promover uma vida digna aos homens. Em sentido contrário, seu uso abusivo ocasionou inclusive inúmeras injustiças sociais, intensificando-se depois da Revolução Industrial.

Insatisfeito, o povo passou a buscar melhores condições de saúde, trabalho, educação, lazer e econômicas. Diante do movimento social, o Estado de Direito quase foi rompido. Não podendo mais se justificar como liberal, precisou abrir mão de sua neutralidade e agregar-se a sociedade, sem, contudo renunciar ao primado do Direito, ou seja, apesar de ter cedido às pressões sociais manteve o primado da lei.

Então, o Estado Social de Direito, continua sendo um Estado submisso à lei, mas não a qualquer lei e sim a lei que vise o bem estar social.

A passagem do Estado de Direito para o Estado de bem estar social (Welfare State) marca a transformação de um Estado abstencionista norteado pelo princípio da liberdade em um Estado intervencionista, pautado no princípio da igualdade material, ou ainda,

\footnotetext{
${ }^{2}$ A célebre máxima da escola fisiocrata francesa do século XVIII "Laissez faire, laissez passer: le monde va de lui même" ("deixa fazer, deixa passar: o mundo anda por si mesmo") é a que melhor expressa a natureza da economia liberal, ou seja, pode ser considerada como expressão-símbolo do liberalismo econômico. Representa a versão mais pura de capitalismo em que o mercado deve funcionar livremente, sem interferência.
} 
poderíamos dizer que deixa de ser um Estado mais livre e menos justo para ser menos livre porém mais justo.

Quanto a esta transformação do Estado Liberal em Estado Social de Direito, importantes as palavras do jurista Jorge Miranda:

\begin{abstract}
Século marcado por convulsões bélicas, crises econômicas, mudanças sociais e culturais e progresso técnico sem precedentes (mas não sem contradições), o século XX é, muito mais do que o século anterior, a era das ideologias e das revoluções. Desembocam nele todas as grandes correntes filosóficas e acelera-se o ritmo dos eventos políticos. É, portanto, o século em que o Direito Público sofre poderosíssimos embates e em que a fase liberal do Estado constitucional vai seguir-se uma fase social (2000, p. 88$)$.
\end{abstract}

Inobstante o fato do Estado Social de Direito pautar-se pela busca da realização do bem estar social, ainda não podemos caracterizá-lo como um Estado Democrático de Direito, tendo em vista que este último necessita de determinado fator que alguns Estados Sociais não apresentaram. Tal fator consiste na legitimidade do exercício do poder político.

Classicamente, se entende a Democracia como um governo do povo, para o povo e pelo povo que exerce diretamente ou via representantes. A origem etimológica da palavra "democracia" advém da expressão grega demos que significa povo e kratos que significa poder.

Diante do exposto acima podemos dizer que o conceito de Estado Democrático de Direito é correlato a um outro conceito, o da legitimidade, na medida em que esta - como sendo o respaldo daquele que exerce o poder político na vontade popular - é pressuposto daquele, ou seja, sem legitimidade não há democracia.

Neste sentido, o Estado Democrático de Direito consiste em um Estado no qual a preponderância da vontade popular na sua organização política, social, econômica e ideológica é característica basilar.

Quanto à configuração do Estado Democrático de Direito mister salientar o que ensina a doutrina de José Afonso da Silva, que assevera que "não significa unir formalmente os conceitos de Estado Democrático e Estado de Direito" (1999, p. 119). Para este importante jurista, consiste na criação de um novo conceito, levando em conta os 
conceitos dos elementos componentes, mas os supera na medida em que incorpora um componente revolucionário de transformação do status quo ${ }^{3}$.

Ao tratar da importância da Constituição Federal de 1988, Bedin e Santos destacam que "de fato, a nova Constituição deu ao Brasil um arcabouço jurídico-político fundamental. Nesta nova configuração, ganhou destaque o forte reconhecimento dos direitos humanos (artigos $5^{\circ}$ ao $\left.17 \mathrm{da} \mathrm{CF}\right) "$ (BEDIN, 2012, p.388).

A Carta Magna brasileira consagra o Estado Democrático de Direito já em seu artigo $1^{\circ}$, arrolando como um de seus fundamentos a dignidade da pessoa humana.

Desta forma, fundamentados em preceitos constitucionais, podemos dizer que o Estado Democrático de Direito está baseado no princípio da legalidade (artigo $5^{\circ}$, II), porém, não na legalidade formal e sim material, a medida em que tem como objetivo a realização de uma sociedade livre, justa e solidária (artigo $3^{\circ}$, I); garantindo o desenvolvimento nacional (artigo $3^{\circ}$, II); erradicando a pobreza, a marginalização e reduzindo as desigualdades sociais e regionais (artigo $3^{\circ}$, III), além de promover o bem de todos, sem preconceitos de raça, cor, sexo, idade e quaisquer outras formas de discriminação (artigo $3^{\circ}, I V$ ). Constitui-se, assim, em democrático forte no que preceitua o parágrafo único do artigo $1^{\circ}$, que determina que "todo poder emana do povo, que o exerce por meio de representantes eleitos ou diretamente, nos termos da Constituição".

Diante destes aspectos poderíamos definir o Estado Democrático de Direito como qualquer Estado que se aplica a garantir o respeito das liberdades civis, ou seja, o respeito pelos direitos humanos e pelas garantias fundamentais, através do estabelecimento de uma proteção jurídica, ou em outras palavras, aquele Estado que busca a realização do bem estar social sob a égide de uma lei justa e que assegure a participação mais ampla possível do povo, no processo político decisório.

\section{O DIREITO À SAÚDE COMO DIREITO FUNDAMENTAL: A TUTELA DA SAÚdE PELA DECLARAÇÃO UNIVERSAL DOS DIREITOS HUMANOS E PELA LEGISLAÇÃO PÁTRIA BRASILEIRA}

\footnotetext{
${ }^{3} \mathrm{O}$ conceito inicial do status quo tem origem na expressão diplomática in statu quo ante bellum, que significa "como era antes da guerra", que significava recuperar a situação de poder e liderança que havia antes de uma guerra.
} 
Ao analisarmos o desenvolvimento social da humanidade e seus direitos fundamentais, conquistados ao longo da história, podemos dizer que os mesmos foram formalmente alçados à categoria de Direitos Humanos propriamente ditos - universais e positivos - em 1948 através da Declaração Universal dos Direitos Humanos. Dentre eles, destacamos o Direito à Saúde, objeto de análise no presente estudo.

Quanto ao direito fundamental à saúde, impossível dissociarmos sua essência do direito à vida. Poderíamos assim dizer que o direito à saúde está intrinsecamente ligado ao direito à vida, fazendo dele parte. Para Nelson Oscar de Souza o direito à vida é o direito primordial: "Sem ele os demais carecem de sentido. Constitui o direito fundamental por excelência. Deste direito decorrem os demais. É o bem maior" (SOUZA, 1998, p. 240).

Para Bedin (2002, p. 44) o direito à vida é um direito elementar que transpassa todo o mundo moderno. Para ele "este direito está tão arraigado em nosso cotidiano que qualquer iniciativa em restringi-lo torna-se, de imediato, uma questão polêmica".

Ainda quanto à importância da saúde enquanto direito fundamental do ser humano, não poderíamos nos eximir de destacar as palavras de Amartya Sem: "a saúde está as mais importantes condições da vida humana e é um constituinte criticamente significativo das capacidades humanas que temos razões para valorizar” (2010, p. 76).

A consciência de que a saúde constitui um direito fundamental - essencial - do ser humano, merecendo atenção especial do Estado quanto à sua proteção e tutela, é uma construção decorrente de uma longa evolução, não apenas do direito em si, mas da idéia de em que consiste a saúde (FIGUEIREDO, 2007, p. 77).

A Declaração Universal dos Direitos Humanos é cristalina ao conferir à "toda" pessoa um padrão de vida suficiente para assegurar a si e a sua família a saúde e o bem estar (artigo XXV da DUDH). Inclusive com direito à alimentação, vestuário, habitação, cuidados médicos e os serviços sociais indispensáveis. O mesmo artigo igualmente garante o direito à segurança em caso de desemprego, doença, invalidez, viuvez, velhice ou outros casos nos quais se configure a perda dos meios de subsistência.

Já o artigo $6^{\circ}$ da Constituição Federal brasileira, por sua vez, relaciona a saúde como direito social, alçando-a ao patamar de direito fundamental. O referido artigo da Carta Magna traz em seu teor que são direitos sociais a educação, a saúde, a alimentação, o 
trabalho, a moradia, o lazer, a segurança, a previdência social, a proteção à maternidade e à infância e a assistência aos desamparados.

O texto contido no artigo 196 da Carta Magna segue no mesmo sentido, estabelecendo de maneira contundente: "A saúde é direito de todos e dever do Estado", devendo ser garantida através de políticas sociais e econômicas com vistas à minoração dos riscos de doença e de outros agravos e propiciando o acesso universal e igualitário às ações e serviços para sua promoção, proteção e recuperação.

Tais artigos foram regulamentados através da Lei 8.080, de 19 de setembro de 1990, a qual dispõe sobre as condições para a promoção, proteção e recuperação da saúde, a organização e o funcionamento dos serviços correspondentes e dá outras providências. Esta lei, em seu artigo $6^{\circ}$, estabelece como campo de atuação do Sistema Único de Saúde SUS - a "formulação da política de medicamentos (...) de interesse para a saúde (...)".

Esta política apresenta um conjunto de diretrizes para alcançar estes objetivos, que incluem como prioridade a revisão permanente da Relação Nacional de Medicamentos Essenciais - RENAME ${ }^{4}$, a reorientação da assistência farmacêutica, a promoção do uso racional de medicamentos e a organização das atividades de Vigilância Sanitária de medicamentos.

Imperioso destacar também o Decreto 7.508 de 28 de junho de 2011, que em seu artigo 28 caput determina os pressupostos para o acesso universal e igualitário à política farmacêutica.

Em atendimento a tais normativos, o Ministério da Saúde publicou a Portaria MS/GM no 533, de 28 de março de 2012, que estabelece o elenco de medicamentos e insumos da Relação Nacional de Medicamentos Essenciais - RENAME. A RENAME/2012 foi elaborada a partir das definições do Decreto ${ }^{\circ} 7.508$, de 28 de junho de 2008 e estruturada de acordo com a Resolução n n $^{\circ}$ /CIT, de 17 de janeiro de 2012. A RENAME/2012 contempla os medicamentos e insumos disponibilizados no SUS por meio do Componente Básico da Assistência Farmacêutica, Componente Estratégico da Assistência Farmacêutica, Componente Especializado da Assistência Farmacêutica, além de determinados medicamentos de uso hospitalar.

\footnotetext{
${ }^{4}$ A Relação Nacional de Medicamentos Essenciais (RENAME) é uma publicação do Ministério da Saúde na qual constam os medicamentos referendados para combater as doenças mais comuns que atingem a população brasileira. Os estados utilizam a RENAME para elaborar suas listas de assistência farmacêutica básica.
} 
Assim, dada a importância do direito à saúde, eis que diretamente relacionado com o direito à vida, e sua evolução histórica, acompanhando o desenvolvimento da sociedade moderna, podemos dizer que o direito à saúde é um direito social que apresenta uma dupla dimensão defensiva e prestacional. Na condição de direito de defesa - liberdade negativa - o direito à saúde está relacionado ao direito de respeito, o que Figueiredo explica como "não afetar a saúde de alguém, mas, sim, preservá-la" (2007, p. 88).

Dado o direito positivado como vimos acima, podemos concluir no sentido da real existência de um dever que incumbe ao Estado no sentido de executar medidas concretas para a efetivação da saúde pública. Nesta senda, o cidadão seria o titular deste direito, podendo exigir sua prestação, seja ela normativa ou material.

\section{O FENÔMENO DA JUDICIALIZAÇÃo DAS POLÍTICAS PÚBLICAS DE SAÚDE NO BRASIL: INTERVENÇÃO EXCESSIVA DO PODER JUDICIÁRIO VERSUS OMISSÃO ESTATAL}

Ocorre que, diante da evidente positivação do direito à saúde, do acesso cada vez mais facilitado à informação - o que vem sendo fomentado pelos avanços tecnológicos e novas formas de mídia -, bem como da precariedade dos serviços públicos colocados à disposição da população pelo Estado, o cidadão muitas vezes tem se visto obrigado, como única alternativa para ver respeitada sua integridade - ou mesmo de um ente querido -, socorrer-se e abrigar-se sob o manto do Poder Judiciário, requerendo seja determinado o cumprimento do direito do qual o Estado se omitiu de prestar, ou prestou de forma tão deficitária que pode ser considerada inferior ao mínimo exigível.

Nos parece que no Brasil, assim como na maioria dos países em desenvolvimento ou subdesenvolvidos, a estrutura do Estado, seja física ou econômica, não suportou a exponencial gama de direitos concedidos pela Constituição Federal de 88.

Esta falta de estrutura está intrinsecamente ligada a idéia de custo do direito, afinal, há que existir instrumentos capazes de garantir que se cumpram os direitos fundamentais e, se não existem, que sejam urgentemente implementados, no entanto, para 
que se cumpra com essa estrutura mínima capaz de atender toda a população de um país continental como o Brasil, há que se ter recursos públicos, há que se ter orçamento.

Para que se tenha uma idéia da dificuldade de efetivação da universalização dos direitos humanos, mesmo os países europeus enfrentaram o problema do custo do direito, senão com seu próprio povo, com as pessoas que a esses países chegaram em decorrência do fenômeno migratório. Sobre esse aspecto Ferrajoli (2011, p. 481), colocando também em pauta o dilema existente entre a distinção entre homem e cidadão, explicava que "aquellos derechos fueron proclamados como universales sin coste alguno cuando todavia la distinción entre hombre e ciudadano no creaba ningún problema", o que não se previu, segundo ele, foi a possibilidade que "los hombres e mujeres del nuevo mundo pudieram llegar a Europa y pedir el cumplimiento de esa palabra”.

Poderíamos assim dizer que a universalidade dos direitos humanos é um desafio global, destacando sempre que não se trata de uma universalidade de direitos surgidos sob a égide de uma cultura ocidental a ser imposta a todas as culturas sem distinção, mas de uma universalidade moderada que respeite fundamentalmente a dignidade da pessoa humana.

Socorrendo-nos, novamente, dos ensinamentos de Lucas:

o desafio para a universalidade requer empenho para se escapar da sedução dos relativismos e força para fazer a universalidade não um valor entre outros, mas um valor que permite descobrir todos os outros valores, iguais e diferentes, que constituem a aventura humana em sua humanidade (2010, p. 64)

E foi este cenário de exponencialmente crescente número de demandas judiciais nesse segmento - fenômeno conhecido como judicialização da saúde -, que levou o Supremo Tribunal Federal (STF) a realizar, em abril e maio de 2012, uma grande audiência pública em que foram ouvidos especialistas, gestores, magistrados e usuários do Sistema Único de Saúde (SUS). "Este, talvez, seja um dos temas mais desafiadores para o Judiciário, inclusive porque envolve os três poderes constituídos ${ }^{\prime \prime}$, destacou o ministro do STF Gilmar Mendes.

\footnotetext{
5 Informação obtida no portal de notícias do Conselho Nacional de Justiça (http://wwwh.cnj.jus.br/portal/noticias). CNJ. CNJ institui Fórum Nacional do Judiciário para a solução de conflitos na saúde pública. Disponível em: <http://wwwh.cnj.jus.br/portal/noticias/materias-especiais/96noticias/8813-cnj-institui-forum-nacional-do-judiciario-para-a-solucao-de-conflitos-na-saude-publica > Acesso em: 25 ago. 2013.
} 
Entretanto, tais demandas envolvem, dentre outras questões, o fornecimento dos chamados de medicamentos não registrados pela Agência Nacional de Vigilância Sanitária (Anvisa) ${ }^{6}$ ou que estejam ainda em fase experimental. Tal demanda era, e ainda é, tão rotineira que o Conselho Nacional de Justiça expediu em 30 de março de 2010 a Recomendação $\mathrm{n}^{\circ}$ 31, que contém orientações que auxiliam os juízes nas decisões relativas à prestação de serviços de saúde, inclusive sugerindo que os juízes evitem autorizar o fornecimento de medicamentos experimentais ou não registrados no órgão regulador.

Face à evidente positivação do direito à saúde seja a nível internacional na Declaração Universal dos Direitos Humanos, seja a nível nacional no ordenamento pátrio vigente, bem como os demais dados e relatos acima relacionados é que trazemos à baila esta reflexão de grande relevância no cenário brasileiro atual, e que pode ser, talvez a curto ou médio prazo, crucial para a falência ou manutenção dos serviços de saúde no país: Estaria havendo arbitrariedade do Poder Judiciário, à medida que a concessão destes fármacos desbordaria as raias constitucionais? Estaria o Judiciário sendo obrigado a atuar com vistas a suprir a omissão estatal, fazendo cumprir assim o direito à saúde? Diante do crescimento exponencial dos gastos da União com a concessão judicial de medicamentos, não chegaremos em alguns anos a uma falência do sistema de saúde brasieliro?

\section{OS ASPECTOS DESFAVORÁVEIS À JUDICIALIZAÇÃo DAS POLÍTICAS PÚBLICAS}

Dentre alguns dos argumentos utilizados em desfavor do fenômeno da judicialização optamos por trazer à baila os que consideramos os mais relevantes para a presente discussão.

O primeiro argumento que iremos expor consiste no fato de que a norma constitucional aplicável encontra-se positivada na forma de norma programática, ou seja, há previsão cristalina na Constituição Federal de 1988 sobre a responsabilidade da garantia da saúde no país.

\footnotetext{
${ }^{6}$ Criada pela Lei no 9.782, de 26 de janeiro 1999, a Agência Nacional de Vigilância Sanitária (Anvisa) é uma autarquia sob regime especial, que tem como área de atuação não um setor específico da economia, mas todos os setores relacionados a produtos e serviços que possam afetar a saúde da população brasileira.
} 
A medida que o artigo $6^{\circ}$ é claro ao elencar a saúde enquanto direito social, igualmente está previsto no artigo 196 que a mesma é dever do Estado e será garantida mediante políticas públicas. Assim podemos concluir que a judicialização é sim uma espécie de intervenção entre os poderes, eis que nossa Carta Magna determina de forma taxativa que cabe o Executivo e não ao Judiciário aplicar tais políticas sociais e econômicas.

O segundo argumento orienta-se pela justificativa de que as políticas públicas de saúde devem seguir a diretriz de reduzir as desigualdades econômicas e sociais. No entanto é sabido que justamente as pessoas mais necessitadas e carentes vivem à margem da sociedade e não possuem recursos financeiros para a contratação de um advogado, nem mesmo o conhecimento dos trâmites judiciais e do fato de que poderiam demandar judicialmente com o objetivo de ver respeitado o seu direito.

Neste sentido, nos parece que tal situação, além de não amenizar as desigualdades econômicas e sociais acabariam por acentuá-las ainda mais.

Uma terceira vertente trata do chamado $l o b$ da indústria farmacêutica que oferece bonificações pecuniárias, prêmios, viagens como uma espécie de comissão, uma contraprestação aos médicos que optarem por receitar seus medicamentos em detrimento de outros.

Ocorre que a lista de remédios fornecidos pelo Sistema Único de Saúde é composta por medicamentos genéricos, que possuem o mesmo princípio ativo, a mesma fórmula dos medicamentos "de marca", entretanto na maioria dos casos seu valor é consideravelmente mais atrativo.

Assim, a ação judicial que postula exclusivamente pelo remédio de determinado laboratório, ignorando e excluindo a possibilidade de utilização do medicamento fornecido gratuitamente pelo Estado - fármaco este que possui iguais características e mesmo efeito -, parece infundada eis que onera não apenas os cofres públicos, mas por consequência toda a sociedade.

Há também a grande questão - quarto argumento - acerca da universalidade do direito fundamental à saúde, eis que como direito de "todos" não poderia ser concedida apenas àqueles que por ele postulam judicialmente, em detrimento de outros cidadãos igualmente merecedores de tal direito - que estão esperando por atendimento em postos de saúde e hospitais públicos e privados conveniados com o Sistema Único de Saúde. 
Ao abordar a igualdade sem distinção de qualquer natureza José Afonso da Silva ensina que:

\begin{abstract}
Além da base geral em que assenta o princípio da igualdade perante a lei, consistente no tratamento igual a situações iguais e tratamento desigual a situações desiguais, a Constituição veda distinções de qualquer natureza. (SILVA, 1999, p. 226)
\end{abstract}

Neste sentido, poderíamos afirmar que o direito individual não poderia sobrepujar o coletivo, principalmente quando a judicialização descontrolada e exponencialmente majorada a cada ano possa comprometer de forma crítica, ou mesmo ocasionar a falência do sistema de saúde do país, vindo a desamparar toda a sociedade.

Aí então, talvez nem a determinação judicial seja suficiente para abarcar a quantidade crescente de demandas, bem como a total decadência econômica do setor, que já se mostra extremamente precário nos dias atuais.

Neste contexto, traçando um paralelo entre o crescimento exponencial das demandas, bem como dos gastos do Estado - eis que não diretamente proporcionais passamos ao quinto argumento, o aspecto financeiro. Para adentrarmos esta discussão inicialmente lançaremos o Gráfico 1 abaixo, para logo após analisar a realidade fática.

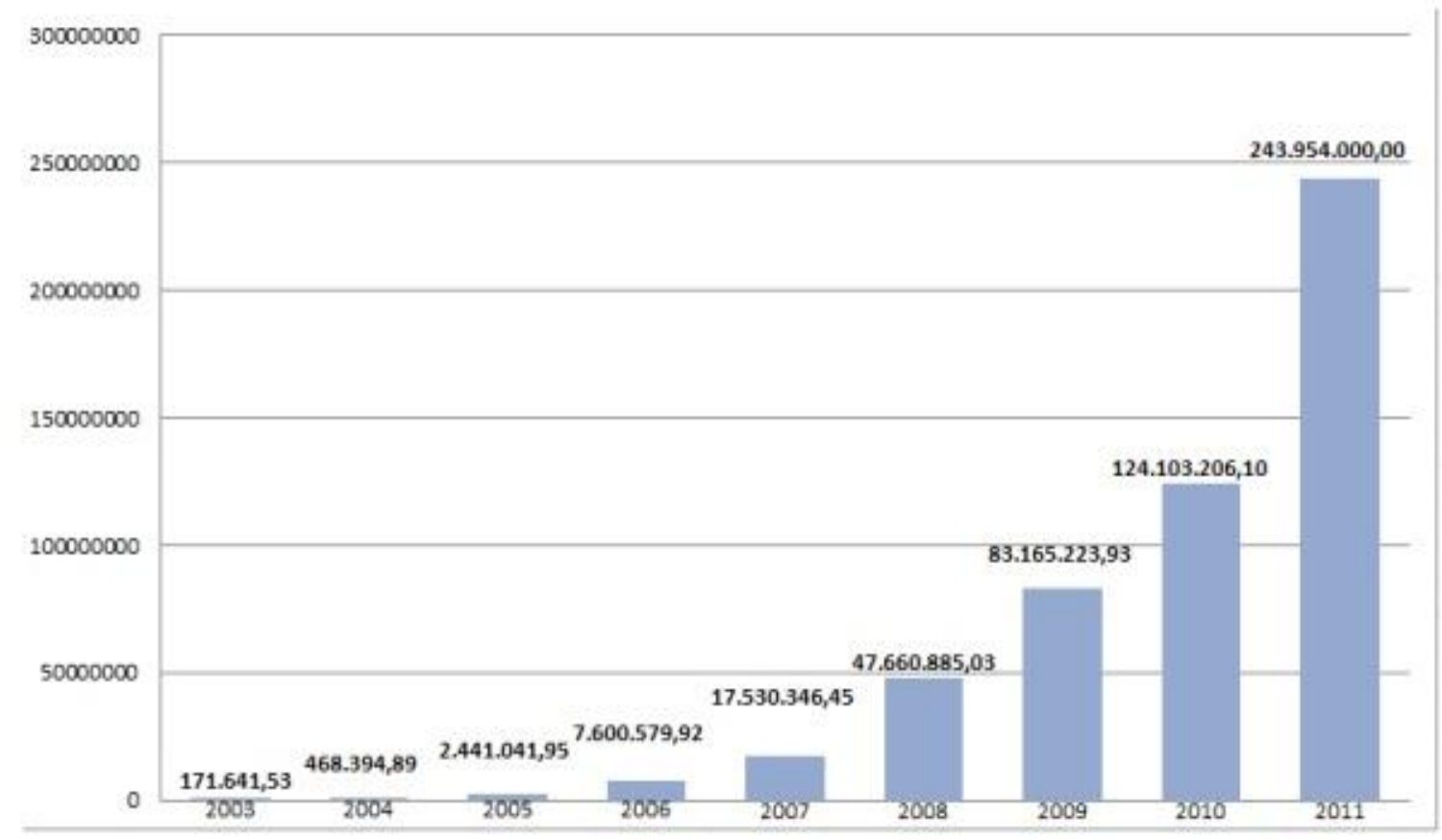

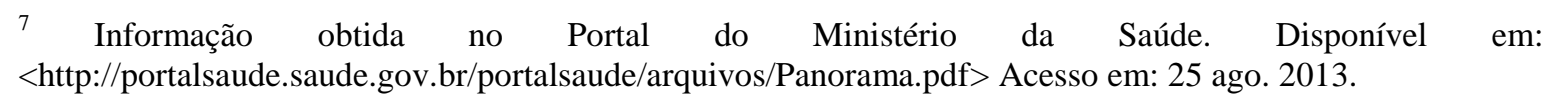


Este gráfico apresenta o montante despendido pelo Ministério da Saúde, ano a ano, com a aquisição de medicamentos, equipamentos e insumos concedidos por decisões judiciais. Não estão incluídos os dados relativos aos valores com despesas de procedimento de compra e entrega do medicamento, pagamento de transportadora para entrega da medicação em domicílio, pagamento de seguro para o transporte do medicamento e, quando necessário, custos com a importação.

Ademais, é sabido que os entes da administração pública adquirem os fármacos para a disponibilização aos cidadãos que deles necessitam - através de licitações públicas. Desta forma, a aquisição dos mesmos medicamentos ou ainda medicamentos não registrados na ANVISA na condição de dispensa de licitação - para se atender às tutelas de emergência - poderá acarretar em um excesso, em mais um ônus por demais gravoso ao orçamento público, ocasionando a possibilidade factível de falência do sistema público de saúde dispensado ao coletivo da população.

Neste mesmo sentido, ao realizarmos um procedimento não previsto na tabela de procedimentos do SUS para apenas um determinado cidadão se estaria, do ponto de vista orçamentário, subtraindo recursos de toda a sociedade, e do ponto de vista legal, violando o dispositivo constitucional que garante o direito à saúde a todos.

É notório que se trata de um crescimento absurdo se considerarmos o transcurso de apenas um período de nove anos. Basta analisarmos os números informados pelo Ministério da Saúde no gráfico acima. Em 2003 foram gastos - considerando apenas os custos com os medicamentos, equipamentos e insumos concedidos em decisões judiciais o valor de $\mathrm{R} \$ 171.641,53$ (cento e setenta e um mil seiscentos e quarenta e um reais e cinquenta e três centavos. Já em 2011 o montante chegou a impressionante cifra de R\$ 243.954.000,00 (duzentos e quarenta e três milhões, novecentos e cinquenta e quatro mil reais). Isto equivale a um aumento percentual de aproximados $142.000 \%$.

Tratam-se de dados alarmantes, que necessitam de uma reflexão crítica por parte de nossa sociedade, bem como dos mandatários do poder de modo que alguma iniciativa seja tomada antes que seja tarde. A judicialização parece nitidamente paliativa, eis que não soluciona o problema em sua origem, a precariedade do sistema de saúde no país e o não 
atendimento pelo Estado Democrático de Direito de uma de suas premissas constitucionais, qual seja a de pautar-se pela dignidade da pessoa humana.

\section{CONSIDERAÇÕES FINAIS}

Diante da realidade apontada no presente estudo, torna-se impossível não cogitarmos a hipótese de que a continuidade da intervenção judicial nas políticas públicas relacionadas à área da saúde acabará por levar todo o sistema à falência, isto sem falar no privilégio concedido ao individual em detrimento da coletividade.

Considerando que se trata de uma demanda que ano após ano cresce exorbitantemente, conforme comprova o gráfico acima, e, se considerarmos astronômico o fato que no ano de 2011 as despesas com os medicamentos, equipamentos e insumos concedidos em decisões judiciais chegaram à impressionante cifra de $\mathrm{R} \$ 243.9$ milhões é de bom alvitre que tomemos conhecimento então que os dados parciais do ano de 2012 compondo os gastos de janeiro à outubro - chegaram à cifra de $\mathrm{R}$ \$ 339,7 milhões.

Assim, diante da escassez e a precariedade dos orçamentos públicos, que se manifesta através da calamidade enfrentada pelo sistema público de saúde - manifestado pela falta de médicos, leitos hospitalares, condições dignas de atendimento à população -, bem como do crescimento exponencial dos gastos com a compra de medicamentos por determinação judicial, entendemos que, não tomadas medidas urgentes, é possível vislumbrar um iminente colapso da saúde no Brasil.

O que se percebe é que grande parte das políticas públicas necessárias são ineficientes ou inexistentes e, por mais que sejamos um dos países com a maior carga tributária do planeta - senão o maior -, milhões de reais são desviados anualmente por meio da corrupção.

Muito embora haja vasta regulamentação sobre a matéria, bem como a consciência geral da precariedade da orçamentação para a área da saúde a nível nacional, inúmeras demandas continuam a ser distribuídas diariamente nas varas competentes e deferidas pelo Judiciário, sem maiores critérios e muitas vezes sem prévia análise técnica, inclusive sem se ater aos medicamentos constantes da RENAME. 
Diante disto temos que analisar a seguinte premissa: no Direito, se alguém está sendo desonerado, outrem poderá estar sendo onerado, neste caso toda a sociedade brasileira.

O que nos parece uma certeza é que a observância do direito à saúde depende de uma organização prévia por parte do Estado Democrático de Direito em definir a verba orçamentária, bem como traçar políticas públicas efetivas relacionadas à área, ou seja, carece de planejamento procedimental e estrutural realmente efetivos. Caso contrário, mantendo-se a situação da forma que atualmente se apresenta, continuaremos a vislumbrar situações de caos onde o Estado nem de longe cumpre com seu dever legal de garantir a saúde - enquanto direito fundamental - aos cidadãos.

Para tanto nos parece que se faz imperioso adotarmos uma análise mais criteriosa por parte do Poder Judiciário nas ações pertinentes a pedidos de medicamentos. Não se trata de cessar a judicialização de imediato, eis que parece evidente que o Estado atualmente mostra-se muito aquém do dever que possui de cumprir quanto aos direitos fundamentais em todas as suas categorias, precisa-se apenas apreciar a concessão do direito postulado àqueles que efetivamente lhe fazem jus.

Há que se levar em consideração as palavras de Bobbio quando ensina que a Declaração Universal dos Direitos Humanos “é apenas o início de um longo processo, cuja realização final ainda não somos capazes de ver”. (BOBBIO, 2004, p.26).

Por fim, a presente reflexão busca instigar a sociedade a não se acomodar diante da situação que está diante de nossos olhos, de fomentar a busca e também a cobrança de atitudes e alternativas por parte de nossos representantes, para que enfim um dia possamos ver perfectibilizado o que preconiza a Declaração Universal dos Direitos do Homem, e que efetivamente toda pessoa tenha direito a um padrão de vida capaz de assegurar a si e a sua família saúde e bem estar, inclusive alimentação, vestuário, habitação, cuidados médicos e os serviços sociais indispensáveis, e direito à segurança em caso de desemprego, doença, invalidez, viuvez, velhice ou outros casos de perda dos meios de subsistência fora de seu controle.

\section{REFERÊNCIAS BIBLIOGRÁFICAS}


BEDIN, Gilmar Antônio. Os direitos do homem e o neoliberalismo. Ijuí: Unijuí, 2002.

BEDIN, Gilmar Antônio; SANTOS, Darlan Machado. Estado de bem-estar social e políticas públicas compensatórias. In: BEDIN, Gilmar Antônio (org.). Cidadania, direitos humanos e equidade. Ijuí: Unijuí, 2012.

BOBBIO, Norberto. A era dos direitos. Rio de Janeiro: Elsevier, 2004.

BONAVIDES, Paulo. Curso de direito constitucional. 7. ed. São Paulo: Malheiros, 1997.

BRASIL. Constituição Federal. Brasília: Senado Federal, 1988. Disponível em: <http://www.planalto.gov.br/ccivil_03/constituicao/constituicaocompilado.htm>. Acesso em: 25 ago. 2013.

BRASIL. Código Civil. Brasília: Senado Federal, 2002. Disponível em: <http://www.planalto.gov.br/ccivil_03/leis/2002/110406.htm>. Acesso em: 25 ago. 2013.

BRASIL. Decreto $n^{\circ} 7.508$, de 28 de junho de 2008. Regulamenta a Lei no 8.080 , de 19 de setembro de 1990, para dispor sobre a organização do Sistema Único de Saúde - SUS, o planejamento da saúde, a assistência à saúde e a articulação interfederativa, e dá outras providências. In: Diário Oficial da República Federativa do Brasil, Brasília, DF, 29 jun. 2011. Disponível em: <http://www.planalto.gov.br/ccivil_03/_ato20112014/2011/decreto/D7508.htm> Acesso em: 25 ago. 2013.

BRASIL. Lei $\mathrm{n}^{\circ}$ 8.080, de 19 de setembro de 1990. Dispõe sobre as condições para a promoção, proteção e recuperação da saúde, a organização e o funcionamento dos serviços correspondentes e dá outras providências. In: Diário Oficial da República Federativa do Brasil, Brasília, DF, 20 set. 1990. Disponível em: <http://www.planalto.gov.br/ccivil_03/leis/18080.htm> Acesso em: 25 ago. 2013.

BRASIL. Portaria MS/GM no 533, de 28 de março de 2012. Estabelece o elenco de medicamentos e insumos da Relação Nacional de Medicamentos Essenciais (RENAME) no âmbito do Sistema Único de Saúde (SUS). In: Diário Oficial da República Federativa do Brasil, Brasília, DF, 29 mar. 2012. Disponível em: <http://portal.saude.gov.br/portal/arquivos/pdf/CONITECPORTARIAMS5332012.pdf> Acesso em: 25 ago. 2013.

BRASIL. Recomendação n ${ }^{\circ}$ 31, de 30 de março de 2010 do Conselho Nacional de Justiça. Recomenda aos Tribunais a adoção de medidas visando a melhor subsidiar os magistrados e demais operadores do direito, para assegurar maior eficiência na solução das demandas judiciais envolvendo a assistência à saúde. In: Diário Oficial da República Federativa do Brasil, Brasília, DF, 07 abr. 2010. Disponível em: <http://www.cnj.jus.br/images/stories/docs_cnj/recomendacoes/reccnj_31.pdf $>$ Acesso em: 25 ago. 2013.

BRASIL. Supremo Tribunal Federal. Dever do Estado de fornecer medicamento não registrado pela ANVISA. Recurso extraordinário $n^{\circ}$ 657718. União, Estado de Minas Gerais e Alcirene de Oliveira. Relator: Min. Marco Aurélio. Reconhecida existência de 
repercussão geral em 18 de novembro de 2011. Pendente de julgamento. Disponível em: $<$ http://www.stf.jus.br/portal/jurisprudenciaRepercussao/verAndamentoProcesso.asp?incid ente $=4143144>$. Acesso em: 25 ago. 2013.

CASTELLS, Manuel. A sociedade em rede. 7. ed. São Paulo: Paz e Terra, 2003.

CNJ. CNJ institui Fórum Nacional do Judiciário para a solução de conflitos na saúde pública. Disponível em: <http://wwwh.cnj.jus.br/portal/noticias/materias-especiais/96noticias/8813-cnj-institui-forum-nacional-do-judiciario-para-a-solucao-de-conflitos-nasaude-publica> Acesso em: 25 ago. 2013.

FERRAJOLI, Luigi. Principia iuris. Teoria del derecho y de la democracia. Madrid: Editorial Trotta, 2011.

FIGUEIREDO, Mariana Filchtiner. Direito fundamental à saúde: parâmetros para sua eficácia e efetividade. Porto Alegre: Livraria do Advogado, 2007.

LUCAS, Doglas Cesar. Direitos humanos e interculturalidade: um diálogo entre a igualdade e a diferença. Ijuí: Unijuí, 2010.

MIRANDA, Jorge. Manual de direito constitucional. 3. ed. Rio de Janeiro: Coimbra Editora, 2000.

MORAES, Alexandre de. Direito constitucional. São Paulo: Atlas, 2010.

MORAIS, Jose Luiz Bolzan; SPENGLER, Fabiana Marion. Mediação e arbitragem: alternativa à jurisdição! 3. ed. Porto Alegre: Livraria do Advogado, 2012.

ORGANIZAÇÃO DAS NAÇÕES UNIDAS. Declaração Universal dos Direitos $\begin{array}{llll}\text { Humanos. } & \text { ONU, } & \text { Disponível }\end{array}$ <http://portal.mj.gov.br/sedh/ct/legis_intern/ddh_bib_inter_universal.htm> Acesso em: 25 ago. 2013.

SEN, Amartya; KLIKSBERG, Bernardo. As pessoas em primeiro lugar: a ética do desenvolvimento e os problemas do mundo globalizado. São Paulo: Companhia das Letras: 2010 .

SILVA, José Afonso da. Curso de direito constitucional positivo. $16^{\text {a }}$ ed. São Paulo: Malheiros, 1999.

SOUZA, Nelson Oscar de. Manual de direito constitucional. Rio de Janeiro: Foorense, 1999.

WOLKMER, Antonio Carlos. Direitos humanos: novas dimensões e novas fundamentações. Revista Direito em Debate, Ijuí, v. 11, n. 16-17, p. 9-32, jan/jun. 2002 